\title{
Solubility of Benzo[a]pyrene and Organic Matter of Soil in Subcritical Water
}

\author{
Svetlana Sushkova, ${ }^{1,}{ }^{*}$ Tatiana Minkina, ${ }^{1}$ Saglara Mandzhieva, ${ }^{1}$ Irina Tjurina, ${ }^{1}$ Olga Bolotova, ${ }^{1}$ Galina Vasilyeva, ${ }^{2}$ \\ Palma Orlović-Leko, ${ }^{3}$ Tatiana Varduni, ${ }^{1}$ Rıdvan Kızılkaya, ${ }^{4}$ Izzet Akca ${ }^{4}$
}

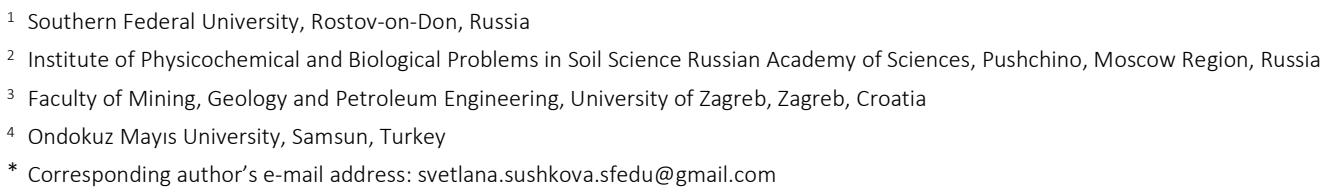

RECEIVED: April 9, 2015 * REVISED: August 14, 2015 * ACCEPTED: September 14, 2015

\begin{abstract}
A dynamic subcritical water extraction method of benzo[a]pyrene from soils is under consideration. The optimum conditions for benzo[a]pyrene extraction from soil are described including the soil treatment by subcritical water at $250{ }^{\circ} \mathrm{C}$ and $100 \mathrm{~atm}$ for $30 \mathrm{~min}$. The effectiveness of developed method was determined using the matrix spiking recovery technique. A comparative analysis was made to evaluate the results of benzo[a]pyrene extraction from soils using the subcritical water and organic solvents. The advantages of the subcritical water extraction involve the use of ecologically friendly solvent, a shorter time for the analysis and a higher amount of benzo[a]pyrene extracted from soil $(96 \%)$. The influence of subcritical water extraction on soil properties was measured the investigation of the processes occurring within soil under the influence the high temperature and pressure. Under appropriate conditions of the experiment there is the destruction of the soil organic matter while the composition of the soil mineral fraction remains practically unchanged.
\end{abstract}

Keywords: benzo[a]pyrene, subcritical water, extraction, soil.

\section{INTRODUCTION}

$\mathbf{P}$ OLYCYCLIC aromatic hydrocarbons (PAHs) are a typical class of persistent organic compounds derived from natural sources such as forest fires or/and anthropogenic urban and industrial processes, and are prevalent in the environment. ${ }^{[1]}$ Sixteen PAHs compounds have been recommended as priority pollutants by the United States Environmental Protection Agency (USEPA) because of their carcinogenicity, mutagenicity, and toxicity. ${ }^{[1-3]}$ These compounds are likely to accumulate in soils for many years because of their persistence and hydrophobicity. As a result, soils may be an important reservoir of PAHs.

Benzo[a]pyrene $(\mathrm{BaP})$ is most frequently considered as the main marker of soil contamination by PAHs, because this is the most prevalent PAH characterized by a very high persistence in environmental objects and elevated carcinogenicity and mutagenicity. ${ }^{[3]} \mathrm{BaP}$ is a compound of hazard class I; it is included in the group of super toxic compounds, and its content in all objects of the ecosystem is subject of mandatory control. ${ }^{[1]}$

Recent reviews ${ }^{[1,3-6]}$ and research papers ${ }^{[7-14]}$ describe and evaluate modern methods for extracting $\mathrm{BaP}$ and other PAHs in environmental matrices and food. Common methodologies for PAH quantification in environmental samples include solvent extraction and analysis by high-performance liquid chromatography (HPLC) with fluorescence detection or by GC-MS. Solvent-based extraction methods of soil, sediments or sludge samples are generally carried out using Soxhlet apparatus, ${ }^{[9]}$ ultrasonication, ${ }^{[15]}$ microwave-assisted extraction, pressurized liquid extraction or accelerated solvent extraction. ${ }^{[6]}$ Solvents include $n$-hexane, acetone, dichloromethane, toluene and others. The extract volume is reduced under nitrogen or by rotary evaporation to a final volume less than $1 \mathrm{ml}$. The procedure may also include extract cleanup by solid phase extraction (typically using Florisil, aluminum oxide, or silica gel) before HPLC or GC-MS analysis. 
There are standardized United States Environmental Protection Agency (US EPA) methods for extracting organic pollutants, including PAHs, from environmental solids (soil, sediment and sludge). For example, in method 3540C, PAHs are extracted for more than $8 \mathrm{~h}$ with a mixture of acetone and $n$-hexane in a Soxhlet extractor. ${ }^{[16]}$ In method 3550C, solid samples are extracted with organic solvents combined with ultrasonic treatment. ${ }^{[17]}$ USEPA PAH extraction methods $3545 \mathrm{~A}$ and 3561 are based on extraction with organic solvents ${ }^{[18]}$ or organic solvents (dichloromethane in particular) in combination with supercritical carbon dioxide $\left(31.2{ }^{\circ} \mathrm{C}, 72.8 \mathrm{~atm}\right) .{ }^{[19]}$ One of the widespread methods for the determination of PAHs in environmental samples is Soxhlet extraction, using $150 \mathrm{ml}$ per sample by $\mathrm{CH}_{2} \mathrm{Cl}_{2}$-acetone extraction for a period of $18 \mathrm{~h}$. ${ }^{[9]}$

Procedures for environmental monitoring of BaPcontaminated soils in the Russian Federation include four certified methods based on extraction with $n$-hexane ${ }^{[20,21]}$ or benzene with ultrasonic treatment. ${ }^{[22]}$ The saponification method was developed for determination of PAH and other petroleum hydrocarbons in sediments with a high content of organic substances. It is based on sample treatment with a boiling solution of alkali in alcohol, with subsequent extraction of pollutants using $n$-hexane. [23]

All of the above-listed methods are characterized by long and multistage procedures for sample preparation using a large volume of toxic organic solvents, typically $50-450 \mathrm{ml}$ per sample. ${ }^{[24]}$ Some prospective methods were recently developed for PAH extraction from various solid matrices using water or carbon dioxide under sub- or supercritical conditions. Suband supercritical water extractions have become popular green extraction methods for various classes of compounds in numerous environmental, food and pharmaceutical matrices. ${ }^{[7,10]}$ Sub- and supercritical water extractions are also used to extract organic contaminants for food safety analyses and from soils/sediments for environmental monitoring purposes. The main parameters influencing extraction efficiency are temperature, extraction time, and the addition of modifiers and/or additives.

Subcritical water extraction is one of the most recent techniques developed for extracting organic compounds, including pollutants from environmental matrices and food. ${ }^{[10,25-32]}$ This method is based on the use of superheated water (100 to $374{ }^{\circ} \mathrm{C}$ and $22.4 \times 106$ Pa pressure) as a solvent in place of organic solvents. Subcritical water has unique characteristics; high temperature and pressure greatly reduce its dielectric constant, surface tension, and viscosity, thereby weakening the hydrogen bonding network of water molecules. ${ }^{[26,33]}$ Increasing temperature from $25{ }^{\circ} \mathrm{C}$ to $350{ }^{\circ} \mathrm{C}$ at a pressure of $10.1 \times 106 \mathrm{~Pa}$ decreases the dielectric constant $(\varepsilon)$ of water from 73 to 2 . Therefore, the solubility of nonpolar compounds increases as temperature increases in this range. For example, the dielectric constant of superheated water is 27 at $250{ }^{\circ} \mathrm{C}$ and $10.1 \times 106$ Pa pressure, which is between that of ethanol $(\varepsilon$ $=24$ at $\left.25^{\circ} \mathrm{C}\right)$ and acetonitrile $\left(\varepsilon=36.2\right.$ at $\left.25^{\circ} \mathrm{C}\right)$, one of the best solvents for BaP. Because superheated water acts as an organic solvent, subcritical water extraction could be categorized as a solvent extraction process. ${ }^{[34]}$ Moreover, superheated water is readily available, non-toxic, reusable and very low in cost as well as environmentally benign. Thus subcritical water extraction has been suggested as an alternative to organic solvents or toxic aqueous liquid media. ${ }^{[27]}$

Presently there are only a few publications on subcritical water extraction of PAHs, and in particular BaP, from solid environmental matrices. Subcritical water extraction of (PAH)-contaminated soil was investigated in conditions using $30 \mathrm{ml}$ water and $10 \mathrm{ml}$ of toluene (for the $300{ }^{\circ} \mathrm{C}$ extractions) or $60 \mathrm{ml}$ water and $20 \mathrm{ml}$ of toluene (for the $250{ }^{\circ} \mathrm{C}$ extractions). ${ }^{[9]}$ In the present study, we have developed a method for coupling static subcritical water extraction with collection on styrene-divinylbenzene (SDB) SPE of disks for quantitative extractions of PAHs from soils, sediments, and air particulate matter. ${ }^{[10]}$ Two papers describe the use of subcritical water extraction of fluoranthene, phenanthrene and pyrene from soil and sediments, ${ }^{[34,35]}$ but to our knowledge there is no information on the use of these methods for analysis of soil samples and all of them describe methods used in subcritical water extraction with organic solvents added.

The main aim of this study was to develop a dynamic subcritical water extraction method of BaP from soil and to measure the influence of subcritical water extraction on main soil properties.

\section{EXPERIMENTAL}

Sampling of soil (carbonate heavy loamy chernozem, virgin, the $0-5 \mathrm{~cm}$ topsoil) was carried out in the Persianovskaya steppe of the Rostov region (South of Russian Federation) located far from possible contamination sources. This soil revealed the following physical and chemical properties: organic carbon $\left(\mathrm{C}_{\mathrm{org}}\right)=3.4 \%$; $\mathrm{pH}=7.3$; cation exchange capacity $(\mathrm{CEC})=37.1 \mathrm{mmol}(+) / 100 \mathrm{~g} ; \mathrm{CaCO}_{3}=0.1 \%$; the content of physical clay $=53.1 \%$ and clay $=32.4 \%$.

Soil properties were analyzed using Russian standard methods (Table 1). ${ }^{[36]}$ Soil organic carbon was measured using $0.4 \mathrm{~N}$ ( $\mathrm{N}$ convert in $\mathrm{M}$ ) potassium bichromate (the Tyurin method modified by Simakov). Water-soluble organic matter in soil extracts was determined according to methods of Sokolov. ${ }^{[36]}$ Soil organic carbon total content was determined by method of direct burning. Soil particle size distribution (silt and clay content) was determined by the pipette method after the pyrophosphate treatment. CEC of the soil 
Table 1. BaP content extracted from the chernozem by subcritical water depending on temperature and time of extraction, expressed in $\mu \mathrm{g} / \mathrm{kg}(N=9)$

\begin{tabular}{cccc}
\hline \multirow{2}{*}{$\begin{array}{c}\text { Temperature of } \\
\text { extraction } /{ }^{\circ} \mathrm{C}\end{array}$} & \multicolumn{3}{c}{ Extraction time / $\mathrm{min}^{(\mathrm{a})}$} \\
\cline { 2 - 4 } & 20 & 30 & 40 \\
\hline 230 & $26.0 \pm 1.2$ & $23.6 \pm 1.4$ & $22.8 \pm 2.2$ \\
240 & $34.0 \pm 1.4$ & $31.5 \pm 1.8$ & $30.2 \pm 3.5$ \\
250 & $43.7 \pm 4.7$ & $39.5 \pm 3.2$ & $35.4 \pm 1.8$ \\
260 & $31.5 \pm 3.8$ & $27.6 \pm 2.3$ & $23.6 \pm 3.1$ \\
270 & $21.0 \pm 0.8$ & $19.7 \pm 1.6$ & $15.8 \pm 0.7$ \\
\hline
\end{tabular}

(a) The value means average from 9 replications and standard deviation is given with \pm .

was determined using $1 \mathrm{M}$ ammonium chloride (the BobkoAskinazi method). ${ }^{[36]}$ Soil $\mathrm{pH}$ was measured with a $\mathrm{pH}$ electrode using a 1:5 suspension of a soil to water ratio. Carbonates were measured by the Kudrin method using 0.005 $\mathrm{N}$ ( $\mathrm{N}$ convert in $\mathrm{M}$ ) $\mathrm{H}_{2} \mathrm{SO}_{4}$ and then an excess of the acid was titrated with alkali. ${ }^{[36]}$

Solvents and reagents were HPLC grade and included ethanol (96\%, analytical grade), $n$-hexane ( $99 \%$, analytical grade), potassium hydrate ( $98 \%$, analytical grade), acetonitrile ( $99.9 \%$, analytical grade), $\mathrm{NaOH}$ (97\%, analytical grade), and anhydrous $\mathrm{Na}_{2} \mathrm{SO}_{4}$ (purchased from Aquatest, Rostov on Don, Russia). A BaP standard in acetonitrile (State Standart Sample 7515-98) was used for HPLC analyses.

Subcritical water extraction of BaP from soil samples was performed in a specially developed extraction cartridge made of stainless steel and equipped with screw-on caps at both ends using a specially developed device for dynamic subcritical water extraction. ${ }^{[23,37]}$ It was also equipped with a pressure gauge that included a valve for pressure release to maintain an internal pressure of $100 \mathrm{~atm}$. The extraction cartridge was placed into an oven that was temperature regulated.

The process of $\mathrm{BaP}$ analyses in soil based on subcritical water extraction is schematically shown on Figure 1. It consisted of the following step-by-step operations. An airdried sample of the soil was ground in a porcelain mortar and passed through a $1 \mathrm{~mm}$ sieve. One gram of sample was placed into the extraction cartridge filled by beaten glass with a particles size $0.5 \mathrm{~mm}$ at both ends of cartridge. Then the cartridge was connected to installation where the sample heats up to $250^{\circ} \mathrm{C}$ under continual water flow rate $(0.6$ $\mathrm{ml} / \mathrm{min}$ ) passing through a cartridge under pressure of 100 atm for $15 \mathrm{~min}$. The scheme of device for carrying out process of extraction is submitted on Figure 2.

The cartridge was placed into an oven held at temperatures of $230,240,250,260$ or $270{ }^{\circ} \mathrm{C}$ for 20,30 or 40 $\mathrm{min}$. Subsequent extractions were conducted under optimum conditions ( $30 \mathrm{~min}$ at $250^{\circ} \mathrm{C}$ and $100 \mathrm{~atm}$ ). After cooling, the content of the cartridge was filtered (Whatman no. 1) into a conical glass flask and washed with $2 \mathrm{ml}$ of doubledistilled water. This operation was repeated two or three times, until the filtrate was clear. The aqueous extract was re-extracted three times with $5 \mathrm{ml}$ of $n$-hexane by shaking for $15 \mathrm{~min}$ in a separatory funnel. The hexane extracts were combined and filtered through anhydrous $\mathrm{Na}_{2} \mathrm{SO}_{4}$ and evaporated to dryness in a pear-shaped flask on a vacuum evaporator in a $40^{\circ} \mathrm{C}$ water bath. The residue was dissolved in $1 \mathrm{ml}$ of acetonitrile by shaking for $30 \mathrm{~min}$. The BaP concentration in the acetonitrile extract was determined by HPLC.

The results of the subcritical water extraction of BaP from soil were compared to those obtained by a standard saponification method. ${ }^{[20,38]}$

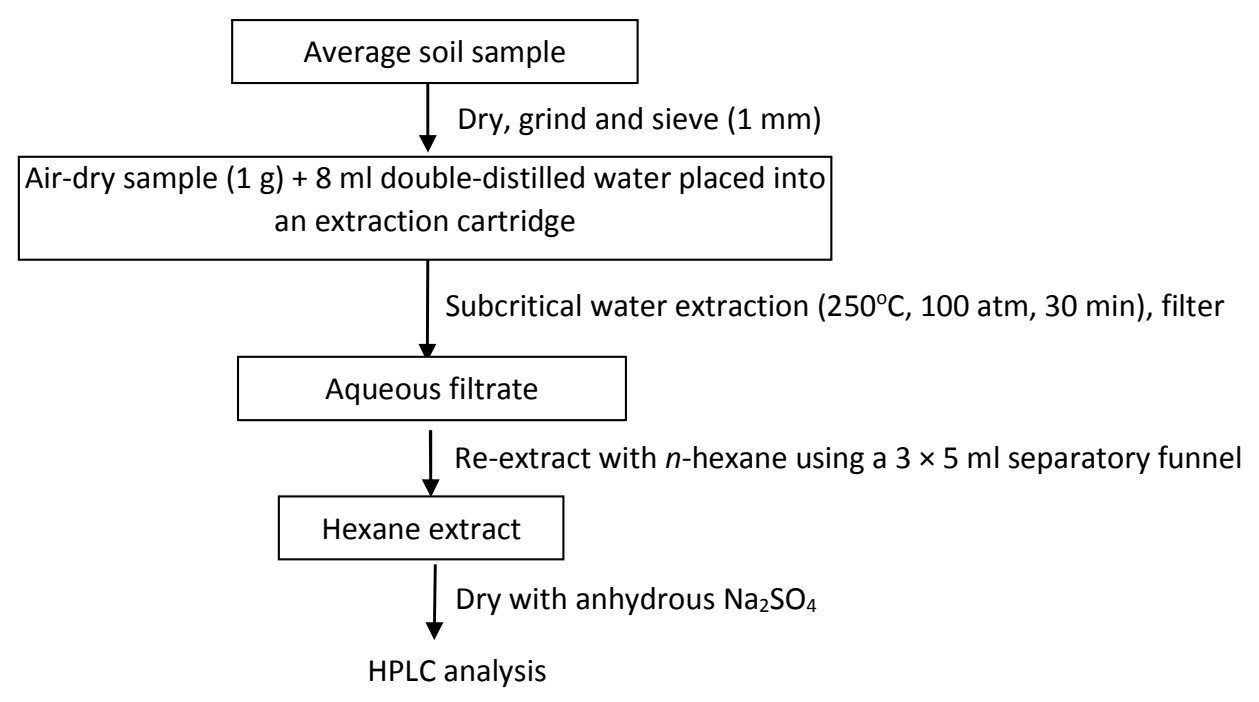

Figure 1. Scheme of BaP analysis in soil material using subcritical water extraction and HPLC analyses of the extract. 


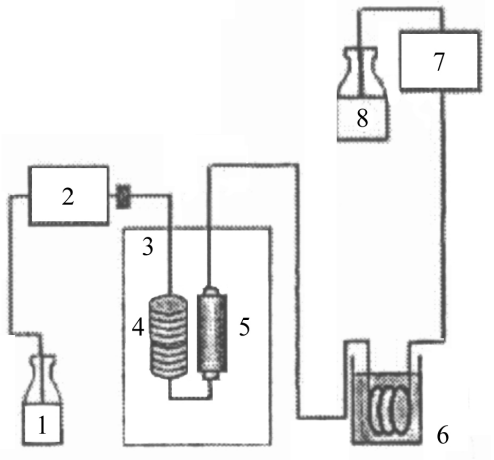

Figure 2. The scheme of installation for subcritical water extraction of BaP (Lekar et al., 2014): 1. Flask for distill water; 2. Pump «Elilex LABS, INC. MENLO PARK, CA» (AA100-S-2 model); 3. Thermostat (furnace electric, HRHK C$242 \varnothing 100 / 179 / 2150 \mathrm{~W}, 230 \mathrm{~V}$ model); 4. Thermostat spiral (the communication of $L=3,5 \mathrm{~m}$ system put in the form of a spiral of $L=12 \mathrm{~cm}) ; 5$. Cartridge $(L=150 \mathrm{~mm}$ stainless steel and internal diameter 4,5mm); 6. Ice bath; 7. Pressure limiter; 8. Flask for collecting extracts. (Borisenko et al., 2009).

The method of saponification involves treating solid material with a boiling mixture of alkali and alcohol, and subsequent extraction of pollutants with $n$-hexane. ${ }^{[23]} \mathrm{A} 1 \mathrm{~g}$ aliquot of air-dried vegetation sample was placed in a conical flask and $30 \mathrm{ml}$ of $2 \%$ solution of $\mathrm{NaOH}$ in ethanol was added. The mixture was boiled on a water bath for $3 \mathrm{~h}$. After cooling, the liquid layer was decanted into another flask and $5 \mathrm{ml}$ of double-distilled water and $15 \mathrm{ml}$ of $n$-hexane were added. The flask was placed on a rotary shaker for 10 min, then transferred to a separator funnel to collect the hexane layer. The hexane extraction was repeated twice. The combined hexane extract was transferred to a conical flask and washed with water until a neutral reaction (using indicator paper), transferred to an amber flask containing 5 g anhydrous $\mathrm{Na}_{2} \mathrm{SO}_{4}$ and allowed to stand overnight at $5{ }^{\circ} \mathrm{C}$. The dehydrated extract was transferred to a round-bottom flask and evaporated to dryness by rotary evaporation in a $40{ }^{\circ} \mathrm{C}$ water bath. The extract residue was dissolved in $1 \mathrm{ml}$ of acetonitrile and analyzed by HPLC.

The efficiency of BaP extraction from soil was determined using the matrix spiking recovery technique. ${ }^{21}$ The air-dried soil sample ( $1 \mathrm{~g}$ ) was placed into a roundbottom flask and BaP standard solution in acetonitrile was added to give $\mathrm{BaP}$ concentrations of 2, 8, 16, 32 and 64 $\mu \mathrm{g} / \mathrm{kg}$ (Table 2). After evaporating the solvent for $30 \mathrm{~min}$ under a hood under ambient conditions, the BaP-spiked soil samples were incubated for $24 \mathrm{~h}$ at $7{ }^{\circ} \mathrm{C}$. The samples were then analyzed by the subcritical extraction method described above. The remaining soil samples were analyzed for traces of BaP. BaP content in the remaining soil samples was less than detection limit of using equipment.

$\mathrm{BaP}$ in the extracts was quantified by HPLC (Model 2000, Thermo Separation Products, Waltham, MA, USA) with simultaneous ultraviolet (UV-1000) and fluorescence (FL-3000) detection following ISO 13877 requirements. ${ }^{[39]}$ The BaP peak on chromatograms of soil sample extracts was identified by comparing retention time to that of the analytical standard sample using the two detectors. The limit of BaP detection and quantification were determined using standard solutions and calibration curves. A calibration standard was inserted after every six samples to correct for drift in retention time within a run.

BaP concentrations in soil samples $(A, \mathrm{ng} / \mathrm{g})$ were calculated as follows:

$$
A=k \cdot \mathrm{SI} \times \operatorname{Cst} \times V /(\text { Sst } \times m)
$$

where Sst and $\mathrm{SI}=$ respective areas of BaP peaks in chromatograms of standard and sample solutions; Cst = BaP concentration in standard solution $(\mathrm{ng} / \mathrm{ml}) ; k=$ coefficient of $\mathrm{BaP}$ recovery from a sample; $V=$ volume of acetonitrile extract used for HPLC (ml); $m=$ mass of the sample (g). Data handling and statistical analyses were conducted using Microsoft Excel.

\section{RESULTS AND DISCUSSION}

It was found that subcritical water extraction allows to simplify process of $\mathrm{BaP}$ extraction from soils at the expense of an exception of organic solvents use and reduction of carrying out time of reaction till 20-40 min instead of 11-48 h, and also reduction of extraction stages number to one stage instead of five on a saponification method. ${ }^{[40,41]}$

The oxidation of the soil lipid fraction and the maximum transition of $\mathrm{BaP}$ into the water solution occur in a hermetic reactor at $230-270{ }^{\circ} \mathrm{C}$ and pressure of 100 atm for 20-40 min (Table 1).

The efficiencies of BaP extraction from spiked soil samples of chernozem ordinary by the two described methods are shown in Table 2. For all BaP concentrations in the soil samples $(30.8-100.3 \mu \mathrm{g} / \mathrm{kg})$, subcritical water extraction recovered substantially more $\mathrm{BaP}$ than the saponification method. Up to $96 \%$ of the BaP was recovered from the soil using subcritical water extraction compared to $73 \%$ recovered by conventional hexane extraction combined with preliminary saponification of the sample. ${ }^{[42]}$ The other advantages of subcritical water extraction are a shorter analysis time and the use of water as an environmentally friendly solvent instead of large volumes of organic solvents. ${ }^{[43]}$ 
Table 2. BaP extraction degree from chernozem using the extraction methods of saponification and subcritical water (N=9)

\begin{tabular}{|c|c|c|c|c|c|}
\hline \multicolumn{2}{|c|}{ Initial BaP in sample / $\mu \mathrm{g} / \mathrm{kg}$} & \multicolumn{2}{|c|}{$\begin{array}{l}\text { BaP content by method of extraction / } \\
\qquad \mu \mathrm{g} / \mathrm{kg}^{\text {(a) }}\end{array}$} & \multicolumn{2}{|c|}{$\begin{array}{l}\text { Extraction efficiency of the method / } \\
\% \text { of initial }\end{array}$} \\
\hline Background & Spike & Saponification & Subcritical water & Saponification & Subcritical water \\
\hline \multirow[t]{5}{*}{$39.5 \pm 3.2$} & 2.0 & $30.8 \pm 2.6$ & $39.6 \pm 2.9$ & 74.2 & 95.4 \\
\hline & 8.0 & $35.0 \pm 3.4$ & $45.6 \pm 4.4$ & 73.7 & 96.1 \\
\hline & 16.0 & $40.7 \pm 6.9$ & $53.7 \pm 6.5$ & 73.5 & 96.7 \\
\hline & 32.0 & $52.8 \pm 7.1$ & $68.0 \pm 9.8$ & 73.9 & 95.2 \\
\hline & 64.0 & $77.0 \pm 11.9$ & $100.3 \pm 11.4$ & 74.4 & 96.9 \\
\hline
\end{tabular}

(a) The value means average from 9 replications and standard deviation is given with \pm .

\section{The Influence of Subcritical Water Extraction on Soil Properties}

Soil samples and soil extracts were investigated at temperatures $120^{\circ} \mathrm{C}$ and $250^{\circ} \mathrm{C}$ and pressure of $100 \mathrm{~atm}$ during 30 min for the analysis of processes happening during subcritical water extraction. The content of the soil organic carbon (Corg) by Tyurin's method in samples decreases during subcritical water extraction from $2.64 \%$ before subcritical water extraction to $0.05 \%$ after subcritical water extraction by temperature $120^{\circ} \mathrm{C}$ and $250{ }^{\circ} \mathrm{C}$ (Table 3). The obtained data showed the decreasing level of soil organic matter content by method of direct burning to more than $60 \%$ after influence of subcritical water extraction on soil samples. Also it is observed increase in water-soluble organic matter in soil extracts at 10-13 times during increasing the temperature of subcritical water extraction, probably due to the organic substance of the soil partial dissolution (Table 3). The change of soil extracts $\mathrm{pH}$ happens towards increase up to $7.5-8.5$ during subcritical water extraction at a temperature $120^{\circ} \mathrm{C}$ and increase at $250{ }^{\circ} \mathrm{C}$.

The initial content of carbonates in chernozem is $0.64 \pm 0.11 \%$ (Figure 3 ). The reduction of carbonates content in the soil during subcritical water extraction at a temperature of $120^{\circ} \mathrm{C}$ is $35-42 \%$ also revealed a total absence of carbonates in soil samples at their processing by subcritical water at a temperature of $250^{\circ} \mathrm{C}$ (Figure 3).
Researches of elements content in soil samples before and after subcritical water extraction doesn't result the essential change of indicators (Table 3 ). Changes of elements content in soil during subcritical water extraction in different temperatures fluctuates from 0.2 to $2.7 \%$.

After extraction by subcritical water at $120^{\circ} \mathrm{C}$ and $250{ }^{\circ} \mathrm{C}$ the content of $\mathrm{Si}, \mathrm{Al}, \mathrm{Fe}, \mathrm{P}, \mathrm{Ca}$ and $\mathrm{Mg}$ oxides in the first case decreased by $4,8,20,33,15,16$ and $12 \%$, respectively, after extraction by subcritical water at $250{ }^{\circ} \mathrm{C}$ the content of $\mathrm{Si}, \mathrm{Al}, \mathrm{Fe}, \mathrm{P}, \mathrm{Ca}$ and $\mathrm{Mg}$ oxides decreased by $6,14,40,40,23,25$ and $19 \%$, respectively (Table 3). It can be explained by dissolution of watersoluble forms of such elements as $\mathrm{Si}, \mathrm{Al}, \mathrm{Fe}, \mathrm{P}, \mathrm{Ca}$ and Mg. ${ }^{[44-46]}$

\section{CONCLUSIONS}

Thus, the dynamic subcritical water extraction method was developed and its efficiency was proved. The most optimum conditions of BaP extraction from chernozem ordinary were determined by treating the soil by subcritical water at $250{ }^{\circ} \mathrm{C}$ and $100 \mathrm{~atm}$ of pressure for $30 \mathrm{~min}$. The developed method allows water to extract to $96 \%$ of the total content of BaP from the soil, that can approved by matrix spiking recovery technique. It exceeds the data obtained

Table 3. Elements content in chernozem before and after subcritical water extraction

\begin{tabular}{|c|c|c|c|c|c|c|c|c|c|c|c|c|c|}
\hline \multirow{2}{*}{$\begin{array}{l}\text { Condition } \\
\text { of the soil }\end{array}$} & $\frac{2}{n}$ & $\frac{O_{N}^{m}}{\varangle}$ & 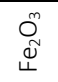 & on & $\begin{array}{l}\stackrel{\sim}{\sim} \\
\text { D. }\end{array}$ & 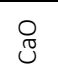 & $\stackrel{\circ}{\mathrm{b}}$ & $\dot{U}$ & $\stackrel{\circ}{\stackrel{O}{c}}$ & $\bar{z}$ & $\vec{\mho}$ & $\stackrel{5}{N}$ & $\stackrel{0}{2}$ \\
\hline & \multicolumn{7}{|c|}{$\%$} & \multicolumn{6}{|c|}{ ppm } \\
\hline $\begin{array}{l}\text { Before subcritical } \\
\text { water extraction }\end{array}$ & 82 & 3.7 & 1.0 & 0.15 & 1.3 & 3.2 & 2.6 & 135.0 & 869.0 & 59.0 & 41.4 & 93.1 & 32.8 \\
\hline $\begin{array}{c}\text { After subcritical } \\
\text { water extraction by } \\
\text { temperature } 120^{\circ} \mathrm{C}\end{array}$ & 79 & 3.4 & 0.8 & 0.10 & 1.1 & 2.7 & 2.3 & 133.2 & 870.9 & 58.4 & 40.7 & 95.6 & 30.5 \\
\hline $\begin{array}{c}\text { After subcritical } \\
\text { water extraction by } \\
\text { temperature } 250^{\circ} \mathrm{C}\end{array}$ & 77 & 3.2 & 0.6 & 0.09 & 1.0 & 2.4 & 2.1 & 132.1 & 863.4 & 57.3 & 39.5 & 94.1 & 31.1 \\
\hline
\end{tabular}


$\mathrm{pH}$ of soil extracts

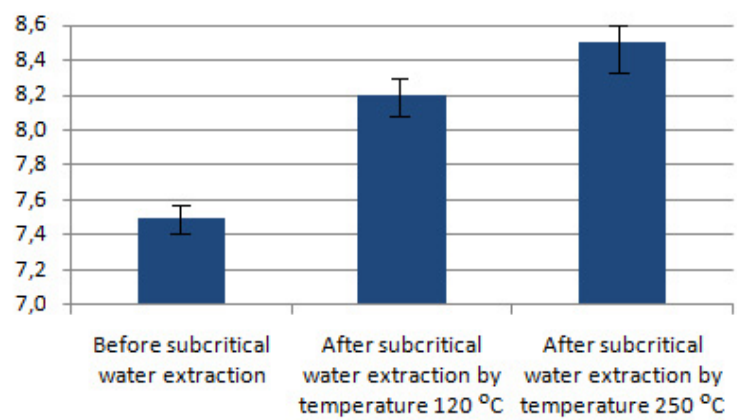

Water soluble organic matter in soil extracts, Csol, \%

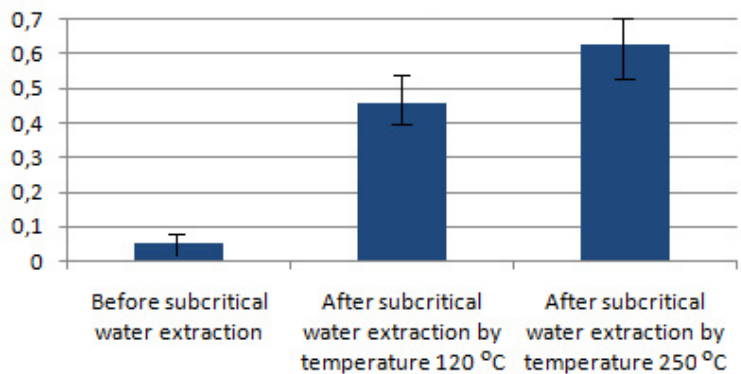

C org content by Tyurin's method, \%

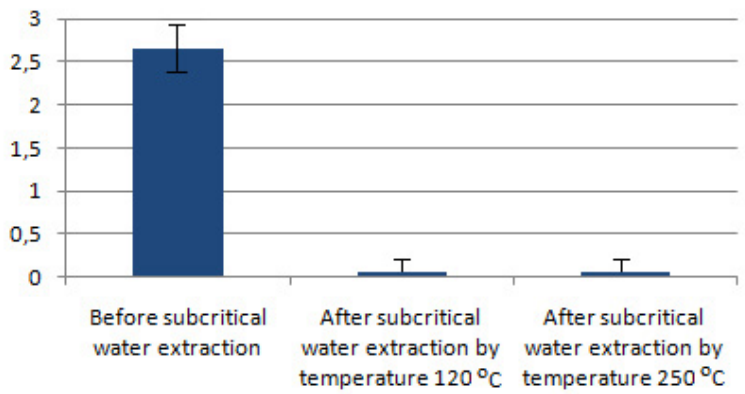

\section{Carbonates content, \%}

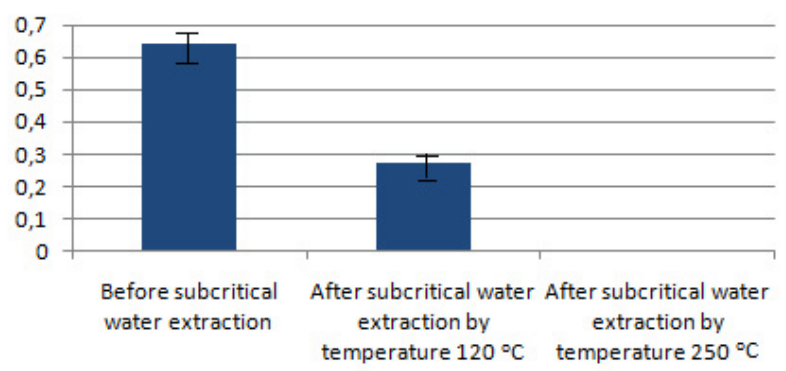

Figure 3. Properties of the soil (chernozem) during subcritical water extraction.

by the method of saponification A $21.5 \%$ increase using the previous noted methods (Table 1). The influence of subcritical water extraction on soil properties was measured for investigation the processes occurring within soil under influence the high temperature and pressure. It was established that all main soil properties changes during subcritical water extraction. The content of water-soluble organic matter and $\mathrm{pH}$ level of soil extracts were increased by increasing the temperature of subcritical water extraction. The content of organic carbon in soil after subcritical water extraction and water-soluble organic matter in soil extracts were decreased by increasing the temperature of subcritical water extraction.
Acknowledgment. This research was supported by projects of the Ministry of Education and Science of Russia, no. 5.885.2014/K, RFBR no. 15-35-21134, Grant of President of Russian Federation no. MK-6827.2015.4. The authors are grateful to academic staff of Laboratory of Sub- and Supercritical Fluid Technologies of Southern Federal University, especially to Nikolay Borisenko, Elena Maksimenko and Anna Lekar, for granting the unique laboratory equipment, valuable scientific materials, consultations on a research subject. Analytical work was carried out on the equipment of Centers for collective use of Southern Federal University "High Technology" grant RFMEFI59414X0002, "Biotechnology, Biomedical and Environmental Monitoring". 


\section{REFERENCES}

[1] T. Wenzl, R. Simon, J. Kleiner, E. Anklam. Trends Anal. Chem. 2006, 25, 716.

[2] X.-h. Li, L.-I. Ma, X.-f. Liu, S. Fu, H.-x. Cheng, X.-b. Xu, J. Environ. Sci. 2006, 5, 944.

[3] V. Camel. Analyst 2001, 126, 1182.

[4] E. Ong, H. Cheong, D. Goh. J. Chromatogr. A 2006, 1112, 92.

[5] F. J. Rivas, J. Hazard. Mater. B 2006, 138, 234.

[6] R. M. Smith, J. Chromatogr. A 2002, 975, 31.

[7] R. S. Ayala, M. D. Luque de Castro, Food Chem. 2001, 75, 109.

[8] P. H. Dyke, PCB and PAH releases from incineration and power generation processes, R\&D Technical Report P 4-052, 1999, Environment Agency, Bristol.

[9] S. B. Hawthorne, C. B. Grabanski, E. Martin, D. J. Miller, J. Chromatogr. A 2000, 892, 421.

[10] S. B. Hawthorne, S. Trembley, C. L. Moniot, C. B. Grabanski, D. J. Miller, J. Chromatogr. A 2000, 886, 237.

[11] J. Li, X. Shanga, Z. Zhaoa, R. L. Tanguaya, Q. Donga, C. Huang. J. Hazard. Mater. 2010, 173, 75.

[12] N. Ratola, A. Alves, S. Lacorte, D. Barcelo, Environ. Monit. Assess. 2012, 184, 985.

[13] P. Oleszczuk, S. Baran, Commun. Soil Sci. Plan. 2007, 38, 171.

[14] O. Zitka, P. Babula, J. Sochor, M. Kummerova, O. Krystofova, V. Adam, L. Havel, M. Beklova, J. Hubalek, R. Kizek, Int. J. Electrochem. Sci. 2012, 7, 908.

[15] C. Domeno, M. Blasco, C. Sanchez, C. Nerin. Anal. Chim. Acta 2006, 569, 103.

[16] US EPA Method 3540C Soxhlet Extraction. The US Environmental Protection Agency (EPA), Rev. 3, 1996, pp. 1-8.

[17] US EPA Method 3550C Ultrasonic Extraction. The US Environmental Protection Agency (EPA), Rev. 3, 2007, pp. 1-17.

[18] US EPA Method 3545A Pressurized Fluid Extraction (PFE). The US Environmental Protection Agency (EPA), Rev. 1, 2007, pp. 1-16.

[19] US EPA Method 3561 Supercritical fluid extraction of polynuclear aromatic hydrocarbons. The US Environmental Protection Agency (EPA), Rev. 0, 1996, pp. 1-14.

[20] Methodical Instructions 4.1.1273-03. Control methods. Chemical factors. Measurement of benz(a)pyrene mass concentration in atmospheric air and in working zone air method by highly effective liquid chromatography method with fluorimetric detecting, 2003, Date of Introduction 01.09.2003 [in Russian]

[21] Procedure of measurements benzo[a]pyrene content in soils, sediments and sludges by highly effective liquid chromatography method, 2008, Certificate 27-08, Moscow.

[22] L. Volkotrub, A. Baushev, Extraction of polycyclic aromatic hydrocarbons from solid samples method, 1994, Patent RU 2018110.

Directive document 52.10.556-95. Methodical Instructions. Definition of Polluting Substances in
Sediments and Suspension. Roshydromet, Moscow, 2002, 21 pp. [in Russian]

[23] E. M. Basova, V. M. Ivanov, Moscow University Bulletin 2011, 52, 163-174.

[24] G. Anitescu, L. L. Tavlarides, J. Supercrit. Fluid. 2006, 38, 167.

[25] A. G. Carr, R. Mammucari and N. R. Foster. Chem. Eng. J. 172 (2011) 1-17.

[26] A. M. Carro, P. Gonzalez and R. A. Lorenzo, J. Chromatogr. A 2013, 1296, 214.

[27] Y.S. Drugov and A.A. Rodin. Sample preparation in the ecological analysis. Anatoly, St. Petersburg, 2002, pp. 749.

[28] D. J. Miller, S. B. Hawthorne, A. A. Clifford, J. Chem. Eng. Data 1998, 43, 1043.

[29] N. Ratola, S. Lacorte, A. Alves and D. Barcelo. J. Chromatogr. A 2006, 1114, 198.

[30] L. Ramos, E. M. Kristenson, U. A. T. Brinkman, J. Chromatogr. A 2002, 975, 3.

[31] L. Turrio-Baldassarri, C. Battistelli, A. lamiceli, Anal. Bioanal. Chem. 2003, 375, 589-595.

[32] A. A. Galkin, V. V. Lunin, Journal Chemistry Successes 2005, 74, 24. [in Russian]

[33] M. Islam, Y.-T. Jo, J.-H. Park, J. Ind. Eng. Chem. 2002, 18, 1689.

[34] A. Latawiec, B. Reid. Chemosphere 2010, 78, 1042.

[35] A. V. Sokolov (Ed.), Agrochemical methods of soil study, 1975, Moscow, Science Publishing, 656 pp. [in Russian]

[36] S. N. Borisenko, M. I. Rudnev, A. V. Bicherov, O. V. Ryabtsova, N. I. Borisenko, E. V. Vetrova, V. I. Minkin, A. V. Lekar. Russ. J. Phys. Chem. B 2009, 7, 100.

[37] A. V. Yaroschuk, E. V. Maksimenko and N. I. Borisenko. Development of benzo[a]pyrene extraction metod from soil. News of Higher Education Institutions. North-Caucasus Region. Natural sciences. Application 2003, 9, 44-46. [in Russian]

[38] ISO 13877-2005, 2005. Soil quality - Determination of polynuclear aromatic hydrocarbons - Method using high -performance liquid chromatography, $p$. 21.

[39] S. N. Sushkova, T. M. Minkina, S. S. Mandzhieva, I. G. Tjurina, World Applied Sciences Journal 2013, 25, 1432

[40] S. N. Sushkova, G. K. Vasilyeva, T. M. Minkina, S. S. Mandzhieva, I. G. Tjurina, S. I. Kolesnikov, R. Kizilkaya, T. Askin, J. Geochem. Explor. 2014, 144, 267.

[41] A. V. Lekar, S. N. Borisenko, E. V. Vetrova, S. N. Sushkova, N. I. Borisenko, Am. J. Agr. Biol. Sci. 2014, 9, 1.

[42] S. Sushkova, T. Minkina, S. Mandzhieva, N. Borisenko, G. Vasilyeva, R. Kızılkaya, T. Aşkın. Eurasian J. Soil Sci. 2015, 4, 15.

[43] J. Neris, S.H. Doerr, M. Tejedor, C. Jiménez and J.M. Hernández-Moreno. Geoderma 2014, 235-236, 240.

[44] A. E. Witter, N. H. Minh, S. Baidar, P. B. Sak, Environ. Pollut. 2014, 185, 59.

[45] M. Kolesár, J. Čurlik. Eurasian J. Soil Sci. 2015, 4, 38. 